\title{
Televisão digital brasileira e os novos processos de produção de conteúdos: os desafios para o comunicador
}

\section{Ana Silvia Lopes Davi Médola}

\section{Resumo}

0 desenvolvimento de conteúdos em plataformas digitais interativas promove alterações estruturais nos fluxos de produção, circulação e consumo de conteúdos midiáticos. Consequência do cenário de convergência dos suportes em redes integradas de telecomunicações, com opções tecnológicas interoperáveis para acesso, processamento e transmissão remota de mensagens, a nova realidade torna cada vez mais tênue os limites dos processos produtivos das mídias tradicionais. No Brasil, a televisão digital aberta e terrestre com recepção móvel, portátil e interativa está em processo de implantação e ilustra as alterações que incidem no planejamento e produção de programas com aplicações multimídia de caráter interativo e pervasivo. 0 presente trabalho propõe refletir sobre a organização da produção de conteúdo para televisão interativa e o lugar do comunicador diante das novas formas de articulação com outras áreas do conhecimento.

\section{Palavras-chave}

Televisão digital. Produção de televisão.

Produção interativa.
Ana Silvia Lopes Davi Médola | asilvia@faac.unesp.br Universidade Estadual Paulista - UNESP. Docente da Faculdade de Arquitetura, Artes e Comunicação, atuação em nível de graduação no Curso de Comunicação Social - Habilitação em Radialismo; em nível de pós-graduação, docente permanente do Programa de PósGraduação em Comunicação e docente permanente do Programa de Pós-graduação em TV Digital.

\section{Introdução}

A chegada da televisão digital no Brasil marca uma nova fase de evolução tecnológica que irá acarretar em transformações profundas em todas as instâncias relativas ao meio. A TV digital traz em seu bojo possibilidades de interatividade no processo de comunicação, redemocratização do acesso à informação, maior incremento à produção audiovisual em níveis nacional e regional, inclusão digital, melhoria da qualidade da educação, enfim, perspectivas de avanços antes muito distantes no contexto da televisão analógica.

Nestes quase 60 anos em operação no país, a trajetória da televisão é, sob certos aspectos, uma experiência bem sucedida. Esse sucesso pode ser dimensionado por indicadores distintos, mas expressivos como o fato de estar presente em mais de 90 por cento dos domicílios (INSTITUTO BRASILEIRO DE GEOGRAFIA E ESTATÍSTICA, 2004), em todos os municípios brasileiros e ser agente de integração sócio-cultural. Com seus altos índices de audiência, faturamento publicitário muito superior às demais mídias, 0 
meio televisão é um dos principais representantes de um sistema de comunicação caracterizado pela concentração de poder sobre os fluxos de informação, com reflexos significativos nas esferas sócio-cultural, política e econômica.

A nova etapa de evolução tecnológica permite disponibilizar uma televisão com transmissão de imagens em alta definição, com 1.080 linhas horizontais, na proporção de tela de 16:9 e áudio com seis canais no Surround 5.1, garantindo qualidade semelhante à encontrada no cinema. Mas a melhor qualidade de imagem e a alta qualidade de som efetivamente não são 0 que a televisão digital oferece de mais inovador. 0 divisor de águas na caracterização do meio é a convergência com a internet, fato que introduz novos usos para este dispositivo, que não apenas os de assistir conteúdos audiovisuais.

Uma gama de serviços interativos passa a compor 0 espectro de funcionalidades da televisão associada à internet. Todos os benefícios da conexão como acesso a vídeos sob demanda, jogos multiplayers, serviços do governo, serviços bancários, contas de e-mail, acesso a redes de compra, redes sociais, bancos de dados passam a estar disponíveis no aparelho de televisão. 0 telespectador sincretiza agora o papel de interagente porque a televisão digital oferece condições de acesso a conteúdos da internet e expande em outros sub-produtos os conteúdos gerados a partir dos programas que exibe. $\mathrm{Ou}$ será dos programas que disponibiliza? Se pensada como televisão que transmite programas em um fluxo temporal, diremos que exibe, mas, inserida nos sistemas de organização de busca por demanda, 0 adequado é a disponibilização. 0 que está implicado em exibir ou disponibilizar informações de interesse do interagente, inclusive sobre as produções da própria televisão, diz respeito à mudança estrutural de que a programação não está mais condicionada aos horários de veiculação no fluxo temporal de transmissão de sinais.

A transição da transmissão analógica para a digital está em curso e, por decreto, (BRASIL, 2006) estabelece que até 20160 sistema analógico deverá ser suspenso no Brasil. Mas as dificuldades enfrentadas durante o primeiro ano de implantação ilustram a dimensão dos obstáculos a serem transpostos para que o sistema seja adotado em toda a sua potencialidade. 0 desenvolvimento do middleware a ser instalado no receptor e codificador de sinais que deverá estar acoplado aos aparelhos analógicos parece estar ainda em fase de conclusão das especificações técnicas. Transposta essa fase, todos os televisores terão que ter instalado o codificador de sinais, e, para que a TV digital seja interativa, será necessário implantar o canal de retorno junto ao sistema.

0 canal de retorno é o responsável pelo fluxo de informações que parte de cada aparelho de televisor e pode ser viabilizado por linha telefônica, internet, TV por assinatura, fibra 
óptica, entre outros. 0 problema é 0 alcance destas tecnologias para atender o contingente potencial de telespectadores da televisão brasileira. Apenas com a superação dos entraves tecnológicos e econômicos implicados no processo de transição, de modo que os aparelhos de televisão estejam equipados para receber os sinais digitais, ou seja, somente com a implantação total da nova tecnologia para os que tiverem um aparelho de televisão, é que poderemos vislumbrar a possibilidade de ações voltadas à inclusão digital de segmentos mais significativos da população.

Como vemos, as questões tecnológicas influem diretamente no tipo de televisão digital a ser implantado, constituindo em grande medida as bases que darão sustentação para novos usos e funções deste meio no contexto de convergência de suportes. 0 comunicador exerce papel fundamental nesta fase de transição na qual está sendo forjado o tipo de televisão a ser adotado. Em um ecossistema midiático em tensão, é necessário estar atento às transformações em curso e procurar refletir criticamente sobre os desdobramentos de uma televisão em processo de convergência com a internet, com novos formatos de conteúdos para atender novas demandas, configurando a 'hipertelevisão' da qual nos fala Scolari:

Si la interfaz de la televisión no permite la interacción, entonces la mejor manera de remediar (Bolter y Grusin, 2000) las experiencias interactivas es simulando la acción de usuario en la pantalla. (...) Las neuvas textualidades televisivas - con sus multipantallas, relatos transmediáticos y multiplicación de los programas narrativos - serían impensables si en la última década millones de usuarios no hubieran vivido experiencias hipertextuales. La hipertelevisión les está hablando a ellos, a los hiperlectores, a los videojugadores, a los televidentes formados en la navegación dentro de entornos interactivos (SCOLARI, 2008, p. 7).

Um novo perfil de público, com interesses diferentes gerados pelos recursos tecnológicos, é a realidade com a qual governo, emissoras, agências de publicidade, anunciantes de instituições públicas e privadas estão se deparando. Trata-se não apenas de mais uma das etapas de transformação evolutiva da televisão, nas quais, sistematicamente, são experimentadas formas de sinergia em função das inovações tecnológicas. Na fase atual, esta sinergia promove a expansão das formas de produção para atender as expectativas de diferentes tipos de usuários em diferentes processos de recepção, decorrência da instituição de novas bases estruturais próprias das tecnologias digitais, conforme veremos adiante.

\section{Televisão digital e as novas demandas de produção}

Os sistemas digitais de comunicação estão estruturados em bases conceituais de produção e circulação de conteúdos diversas da dinâmica dos meios analógicos massivos do século XX, pois introduzem elementos como a conectividade, acessibilidade, ubiquidade 
e pervasividade ${ }^{1}$ nos fluxos comunicacionais.

A televisão digital em implantação no Brasil incorpora as tecnologias infoeletrônicas e aponta para um cenário de profundas transformações no setor em função das possibilidades dos novos dispositivos tecnológicos de geração e difusão de conteúdos audiovisuais. Considerando 0 fato de que o padrão adotado privilegia a transmissão terrestre e aberta, em alta definição, com recursos de mobilidade, portabilidade e interatividade, a produção televisiva sofrerá impactos importantes nas formas de inserção sócio-cultural, sustentação econômica e na estética televisual.

Nesta fase inicial da transmissão em plataforma digital, verifica-se que as estruturas produtivas das empresas consolidadas no sistema de televisão analógico estão passando por uma reconfiguração da lógica de produção consolidada na comunicação de massa, demandando repensar as funções e as rotinas de trabalho do profissional de comunicação neste novo ambiente de produção audiovisual. Com o propósito de preservar ao máximo as bases de sustentação econômica, as empresas de televisão passam a requerer de seus profissionais novas competências diante das exigências da plataforma convergente. Além de um processo contínuo de adaptação às mudanças decorrentes da introdução das constantes inovações tecnológicas, é requerido ao comunicador ações no sentido de prospectar alternativas para os desafios da produção de conteúdos em um novo modelo organizacional da geração, transmissão e comercialização de produtos audiovisuais.

Tal demanda pode ser observada nas construções discursivas em programas de diferentes formatos veiculados nas principais emissoras do país, notadamente com a adoção da interatividade como estratégia enunciativa no plano do conteúdo, vinculada diretamente a ações de comercialização. Embora as propostas interativas ainda não estejam em suporte totalmente convergente, a introdução dos efeitos de sentido de uma comunicação interativa cria modalidades diferentes na maneira de fruição de uma televisão que se propõe expandida, forjando novos hábitos de consumo de conteúdos audiovisuais. 0 exemplo mais recorrente é a convocação para que 0 telespectador acesse 0 site da emissora para obter mais detalhes e informações sobre o conteúdo veiculado na TV, no caso dos programas informativos. Mas também as telenovelas, as séries, os reality shows, todos têm uma página na internet na qual o telespectador poderá encontrar de blogs com participação de autores à ficha técnica da equipe de produção. 
Sabemos que ao longo de sua existência a televisão passou por diferentes fases de desenvolvimento, nas quais o componente tecnológico cumpre importante papel no modo de inserção social do meio e suas formas de consumo, contribuindo para forjar as estéticas televisuais bem como estabelecer parâmetros de organização da produção e sustentação econômica. Da mesma forma, 0 desenvolvimento de conteúdos em plataformas digitais interativas promove alterações estruturais nos fluxos de produção, circulação e consumo de conteúdos midiáticos.

Atualmente, o planejamento de qualquer produção criada e executada para atender às novas tendências de consumo terá que contar com a colaboração de profissionais de outras áreas do conhecimento. É 0 caso do desenvolvimento das interfaces. A introdução de serviços interativos cria modalidades diferentes na forma de fruição de uma televisão expandida (GAWLINSKI, 2003), assim como deve oferecer, num primeiro momento, dificuldades à maior parte da população caso não apresente um elevado grau de usabilidade. Este é um conceito fundamental em TV digital interativa e que pode reduzir o tempo de adaptação da população a essa nova linguagem que busca ainda uma forma expressiva própria. Nesse processo, a usabilidade de interface gráfica desempenha importante papel como facilitadora da comunicação. Dessa forma, o jornalista, 0 roteirista e 0 diretor não podem conduzir as equipes sem considerar a necessidade de interlocução com os profissionais de design para a elaboração da interface interativa.

Também não é possível ao roteirista responsável por uma produção interativa - seja ela jornalística, publicitária, ficcional - não conhecer a lógica da linguagem de programação do middleware que possibilita a adoção dos aplicativos de interatividade. 0 comunicador deve, portanto, estar constantemente atualizado sobre os avanços das bases infoeletrônicas e conhecer as potencialidades e limitações do sistema com vistas a desenvolver soluções de linguagem e formatos para os conteúdos audiovisuais. No caso do Brasil, o middleware adotado é denominado "Ginga". Totalmente desenvolvida no Brasil, esta linguagem declarativa e procedural é destinada à codificação das funções interativas que poderão ser veiculadas em sincronismo com os produtos audiovisuais. Sistema em código aberto, projetado para tornar suas aplicações compatíveis com os demais padrões internacionais, deverá ser implantado nos novos televisores digitais e nos set top box, caixas conversoras de sinais para serem acopladas aos aparelhos analógicos.

Consequência do cenário de convergência dos suportes em redes integradas de telecomunicações, com opções tecnológicas interoperáveis para acesso, processamento e transmissão remota de mensagens, a nova realidade torna cada vez mais tênue os limites 
dos processos produtivos próprios de cada uma das mídias tradicionais. Desta forma, a produção em TV digital sofre profundas mudanças em sua estrutura de base, requerendo um contingente de profissionais com formação de caráter específico, mas com compreensão interdisciplinar da dinâmica da produção de conteúdos que poderão estar sendo consumidos em diferentes ambientes e suportes de recepção. Diante disso, quais os parâmetros para planejar e produzir 0 conteúdo para televisão que poderá ser fruído também tanto no celular, quanto no écran do computador? Quais as estratégias enunciativas capazes de adequar os formatos de modo que possam ser assistidos em variados suportes? Este tipo de questão deve ser motivo de preocupação constante de um fazer enunciativo comprometido com propósito de encontrar formas expressivas capazes de garantir 0 acesso aos conteúdos de parcelas significativas de público, principalmente aquelas ainda excluídas do mundo digital.

Compreendendo que a televisão digital é uma nova mídia em relação à televisão analógica, salientamos que, como todo novo meio, requer ainda 0 desenvolvimento de uma forma expressiva própria que siga uma trajetória semelhante ao desenvolvimento dos demais dispositivos midiáticos. De maneira geral, as mídias em sua fase inicial apresentam seus conteúdos operando com as referências dos meios que os antecederam. No que diz respeito à TV digital interativa, que hibridiza as estruturas de linguagem televisuais e da internet, impõe-se a necessidade de desenvolver sua linguagem sob duas perspectivas: a linguagem de produção de conteúdo e a linguagem de uso na qual o telespectador/usuário deve aprender a interagir com a interface (ROSA, 2005). Ao mesmo tempo em que a produção de conteúdos exige atenção para a diversidade dos dispositivos e modos de recepção, o comunicador não deve negligenciar a necessidade de adequação da linguagem e seus efeitos estéticos para otimizar os processos de interação e comunicação.

A produção, difusão, armazenamento e disponibilização de conteúdos - sejam eles jornalísticos, ficcionais, educativos - requer, portanto, não apenas a compreensão das novas bases estruturais da comunicação na ecologia da convergência, mas também um novo modus operandi no processo produtivo, para que se desenvolvam propostas inovadoras capazes de atender às mudanças nas etapas de produção. Se nos meios analógicos as funções no processo de produção de conteúdos eram mais definidas, na televisão digital as rotinas de produção impõem uma aproximação com os programadores de computador, os designers gráficos e os engenheiros de telecomunicações, para 0 desenvolvimento e execução de um produto audiovisual interativo, por exemplo. Também esses profissionais devem atuar em conjunto no caso das transmissões para aparelhos fixos e móveis, na dinâmica da pervasividade (MÉDOLA; REDOND0, 2008) entre os suportes. Esta prática profissional em nível mais operacional tende a 
reproduzir a lógica colaborativa que incide nas estruturas de códigos abertos da internet e na base da comunicação interativa.

Assim, nas etapas de produção de conteúdos para a TV digital, o comunicador estará necessariamente interagindo com profissionais de outras áreas em um ambiente que requer conhecimentos tecnológicos especializados da comunicação, das engenharias infoeletrônicas e de produção, das ciências da computação, diretamente implicadas no processo de produção audiovisual. 0 desafio para o comunicador é atuar na etapa de implantação da televisão digital como o mediador da produção discursiva em uma cadeia estruturada sob os novos paradigmas das tecnologias da informação e comunicação e que não são mais os mesmos da lógica da televisão analógica. Por isso, na plataforma digital, as empresas produtoras de conteúdos audiovisuais passam a demandar profissionais com novas habilidades e competências de tal modo que a formação dos comunicadores deve assegurar o exercício profissional atento e crítico em relação à inovação em curso.

\section{Inovação tecnológica e novas competências: os desafios para o comunicador}

Certamente as mudanças são graduais e alteram a estrutura organizacional, as funções no processo de produção de conteúdo e as rotinas de trabalho. A adoção de suportes tecnológicos digitalizados para a televisão interfere na dimensão produtiva da comunicação, uma vez que esses dispositivos impõem novos parâmetros de desenvolvimento e gestão das etapas de construção dos conteúdos em um ambiente pautado pela constante inovação tecnológica. Ao caracterizar as inovações, é preciso reiterar que aqui interessa focar a televisão digital enquanto sistema de transmissão de conteúdo audiovisual e de dados, transmitidos por via terrestre a partir de antenas geradoras e retransmissoras do sinal, com possibilidade de estar associada a um canal de retorno. Não estamos envolvendo outras tecnologias televisivas como a televisão transmitida pela internet ou sistemas de transmissão via satélite, linha telefônica e cabo. No entanto, ressaltamos que a sinergia entre esses diferentes sistemas de transmissão em função da evolução dos suportes rumo à interoperabilidade é um dos fatores que certamente deve ser considerado pelos comunicadores nos processos de produção de conteúdos.

Assim como a interatividade, conceito que desperta muito interesse entre os envolvidos com as discussões relativas à televisão digital, vimos que a interoperabilidade, a mobilidade, a portabilidade e a conectividade são conceitos que devem balizar os processos de produção de conteúdo desde a etapa de planejamento até a difusão. 0 contexto de produção estabelecido sobre essa plataforma técnica requer do comunicador uma postura atenta às novas 
possibilidades expressivas da TV digital com os recursos de interatividade, observando as soluções de usabilidade, as metodologias de organização e armazenamento de dados e busca on demand.

Os sistemas de busca on demand, por exemplo, fazem com que os produtos audiovisuais registrados em plataforma analógica como fitas eletromagnéticas estejam passando por processos de digitalização para a preservação dos conteúdos. No entanto, essa preservação adquire novas características, pois requer maior eficiência nas formas de armazenamento para a recuperação de conteúdos em bancos de dados, constituindo ambiente apropriado para a retroalimentação e a geração de novos conhecimentos. Do ponto de vista cultural e histórico, a constituição de bancos de dados e acervos audiovisuais e a acessibilidade pela televisão significam um avanço inestimável aos projetos com fins educativos e de preservação de memória em um país com os problemas e desigualdades do Brasil. Assim, demandas antes não pertencentes às rotinas produtivas da televisão analógica passam a estar mais estreitamente relacionadas às estratégias de produção decorrentes dos processos de convergência midiática.

Também as formas de sustentação econômica sofrem o impacto das mudanças. Os formatos dos programas estão sendo pensados no sentido de contemplar as alternativas de conteúdos capazes de prospectar outras possibilidades de comercialização em um meio que não mais poderá sobreviver apenas com a comercialização de tempo para a veiculação de peças publicitárias. São alternativas em busca de modelo de sustentação de um negócio que passa por profundas alterações. De um lado, as possibilidades tecnológicas de interatividade e, de outro, as particularidades de um telespectador-consumidor, cujos hábitos de consumo se alteram e demandam adequações das emissoras para manterem a atenção do receptor em um sistema midiático marcado pela abundância de produtos e a dispersão da audiência. As tecnologias digitais favorecem a formação de um público 'multimídia' e altamente fragmentado, que consome produtos audiovisuais sob demanda e não está mais somente em frente à televisão.

Produzir conteúdos levando em conta essa realidade é atualmente um desafio para os profissionais de televisão e as referências sobre modelos e esquemas operacionais e gerenciais de produção de conteúdos interativos ainda são escassos. Acreditamos que a observação e 0 acompanhamento das atividades no interior das estruturas organizacionais das empresas de televisão com produção de programas interativos poderão contribuir para a formulação de modelos genéricos capazes de instruir a concepção dos procedimentos necessários à execução deste tipo de produção audiovisual. A elaboração de modelos de referência para o processo de 
produção de conteúdo interativo para televisão digital é objeto de pesquisa, por exemplo, na área de Engenharia de Produção. Nesse sentido, destacamos as propostas de Belda (2009), que utiliza recursos de notação baseados em mapas conceituais e diagramas inspirados em linguagem UML (Unified Modeling Language) com 0 propósito de estabelecer modelagem do processo de desenvolvimento de aplicações para televisão digital educativa. Entretanto, os resultados poderão ser adotados para outros conteúdos que não apenas os educativos.

0 referido estudo revela um adensamento da coordenada vertical do processo de organização de produção para a TV digital, ou seja, a demanda recai principalmente na ampliação das funções na sequência do processo produtivo, de modo que as etapas que vão desde a concepção do produto até a sua comercialização passam a contemplar novas ações e competências. Em todo e qualquer projeto de programa interativo, desde a roteirização até a pós-produção, devem ser considerados aspectos concernentes à estrutura executiva e operacional diante das diferenças de formatos. No entanto, independentemente do formato, a inserção de elementos para uma produção interativa impõe ao comunicador a necessidade de considerar a atuação dos setores vinculados à elaboração de mensagens como as de categorização de acervos, definição de metadados, sincronização de informações e serviços durante 0 fluxo de exibição. Há, portanto, um novo ambiente produtivo que requer a compreensão mais ampliada dos processos executivos e operacionais por parte do comunicador. Esta é uma condição necessária para articulação com os demais profissionais envolvidos na produção e difusão de conteúdos interativos.

A aquisição de outras competências pode ser observada, por exemplo, na etapa de edição, momento do processamento das informações registradas. De acordo com Belda (2009), as máquinas de edição são computadores PC com configurações para a edição de áudio e vídeo, devendo conter placa para a captura do material gravado para o computador e diferentes softwares - entre eles, de edição não-linear de áudio e vídeo, animação em 2D, 3D e Stop Motion. Além disso, devem estar equipadas com softwares de composição de imagem, de criação visual para o desenvolvimento de design gráfico, de softwares e de linguagens de interatividade, como o Ginga (Java TV, NCL Composer), que possibilita a intervenção do telespectador/ interator no conteúdo audiovisual; softwares emuladores de televisão digital para computador, capazes de simular a experiência do set-top box no computador; e softwares de autoração, para finalizar o programa de acordo com 0 formato de exibição (tamanho, codec, plataforma de exibição). A aplicação desses recursos interativos na produção de programas depende, portanto, também do conhecimento do comunicador sobre as funcionalidades dos programas de computador. Isso não significa que o comunicador 
deva dominar os processos operacionais, mas é necessária a compreensão das potencialidades de utilização dos recursos interativos, pois da aquisição dessa competência depende a gestão articulada entre 0 comunicador e os operadores do sistema.

\section{Considerações finais}

Como vemos, a perspectiva de uma abordagem interdisciplinar é fator a ser considerado na organização da produção em televisão e a função do comunicador passa a ser ainda mais especializada, demandando a aquisição de novos saberes. Responsável pela construção discursiva das mensagens, 0 profissional de comunicação é partícipe desde a busca da informação até a formatação mais adequada para a veiculação, agora em diálogo estreito com profissionais de outras áreas. Repensar a atuação no processo de produção de conteúdos para a televisão digital é, portanto, uma exigência que incide atualmente sobre as práticas do comunicador. Ao objetivar produzir um conteúdo interativo, por exemplo, verificase que as ações consolidadas das fases de planejamento, produção e pós-produção do sistema analógico não condizem mais com os procedimentos e as etapas necessárias para a construção de um programa que permita a participação do receptor.

A televisão que conhecemos, a analógica, não é interativa, gera programas em fluxo de tempo real, de um ponto de emissão para vários pontos de recepção, em lógica sequencial, operando com uma audiência "passiva". A internet, mídia interativa que opera por sistema de busca de conteúdos armazenados, tem na ação direta do usuário, por meio de estrutura de navegação hipertextual, condição necessária para que haja uma manifestação textual. A internet requer, portanto, 0 agenciamento do interagente em uma lógica procedimental (MURRAY, 2003). E é a convergência entre os dois meios que promove as alterações nos processos sociais, de gestão e organização da comunicação televisual.

Dessa forma, se a comunicação interativa está edificada sobre bases comunicacionais não pensadas anteriormente, o comunicador terá que aprimorar sua prática. As formas criativas atreladas ao processo de diálogo entre a linguagem audiovisual e o desenvolvimento de softwares e hardwares inauguram efetivamente uma nova realidade no exercício da produção de conteúdos audiovisuais. Aliado a uma revisão profunda dos conceitos relativos às categorizações dos produtos audiovisuais em termos conteudísticos e formais, agora também é necessário ao comunicador estar atento às mudanças estruturais por que passa a televisão contemporânea. Somente assim poderá contribuir intervindo criticamente em um processo em curso, que pode resultar na inclusão digital e social da maioria da população com mais facilidade de acesso à informação e à cultura, por intermédio da televisão digital aberta, gratuita e interativa. 


\section{Referências}

BELDA, Francisco Rolfsen. Um modelo estrutural de conteúdos educativos para televisão digital interativa. 2009. Tese (Doutorado em Engenharia de Produção)- Escola de Engenharia de São Carlos, Universidade de São Paulo, 2009.

BOLTER, Jay Davis; GRUSIN, Richard. Remediation: understand new media. Cambridge: The MIT Press, 2000.

BRASIL. Ministério da Comunicações. DECRET0

No . 5.820, DE 29 DE JUNHO DE 2006 - Dispõe sobre a implantação do SBTVD-T . Brasília, DF, 2006. Disponível em: <http://www.planalto.gov.br/ CCIVIL_03/_Ato2004-2006/2006/Decreto/D5820.htm>. Acesso em: 20 jan. 2009.

GAWLINSKI, Mark. Interactive television production. 0xford: Focal Press, 2003.

INSTITUTO BRASILEIRO DE GEOGRAFIA E ESTATÍSTICA. Pesquisa nacional por amostra de domicílios: síntese de indicadores 2003. Rio de Janeiro, 2004.

MÉDOLA, Ana Silvia; REDOND0, Léo Interatividade e pervasividade na produção da ficção televisiva brasileira no mercado digital. In: ENCONTRO DA UNIÃO LATINA DE ECONOMIA POLÍTICA DA INFORMAÇÃO, DA COMUNICAÇÃO E DA CULTURA - CAPÍTULO BRASIL, 2., 2008, Bauru. Anais... Bauru: ULEPICC, 2008. Disponível em: <www.faac.unesp.br/ ulepicc2008>. Acesso em: 25 jan.2009 .

MURRAY, Janet H. Hamlet no Holodeck: o futuro da narrativa no ciberespaço. São Paulo: Itaú Cultural; UNESP, 2003.

QUIC0, Célia. Televisão digital e interactiva: 0 desafio de adequar a oferta às necessidades e preferências dos utilizadores. In: CONGRESSO DA ASSOCIAÇÃO PORTUGUESA DE CIÊNCIAS DA COMUNICAÇÃO, 3.; CONGRESSO DA FEDERAÇÃO LUSÓFONA DE CIÊNCIAS DA COMUNICAÇÃO, 4.; IBÉRICO, 2., 2005, Covilhã. Estética e Tecnologias da Imagem. Actas... Covilhã: Universidade da Beira Interior, 2005.

ROSA, Almir Antonio. Televisão digital terrestre: sistemas, padrões, modelos. 2005. Tese (Doutorado em Comunicação e Semiótica)- Programa de Estudos Pós-Graduados em Comunicação e Semiótica, Pontifícia Universidade Católica, São Paulo, 2005.

SCOLARI, Carlos. Hacia la hipertelevisión: los primeros síntomas de una nueva configuración del dispositivo televisivo. Diálogos de la Comunicación, [S.l.], n. 77, jul.-dic., 2008.

SQUIRRA, Sebastião; FECHINE, Yvana. (orgs.).

Televisão digital: desafios para a comunicação. Livro da Compós 2009. Porto Alegre: Sulina, 2009.

TEIXEIRA, Lauro. Televisão digital: interação e usabilidade. Goiânia: Ed. UCG, 2009. 


\section{Brazilian digital television and the new content production process: the challenge for the communicator}

\section{Abstract}

Content development in an interactive digital platform promotes structural changes in the fluxes of production, circulation and consumption of contents for the media. As a consequence of the telecommunication web supports convergence scenery with technological options that guarantee access, processing and remote broadcast of messages, the limits of the traditional media productive process has become more pervasive because of the new reality. In Brazil, digital TV for open channels system and with mobile, portable and interactive reception is in process of implantation and it illustrates the changes that reach the planning and production of programs with multimedia applications, which have an interactive and pervasive characteristic. This paper intends to reflect on the steps of content production organization for interactive television, and the place of the communicator facing the new forms of articulation with other areas of knowledge.

\section{Keywords}

Digital television. Television production. Interactive production.

\section{Televisión digital brasileña} y los nuevos procesos de producción de contenidos: los desafíos para el comunicador

\section{Resumen}

El desarrollo de contenidos en plataformas digitales promueve cambios estructurales en los flujos de producción, circulación y consumo de contenidos mediáticos. Como consecuencia del escenario de convergencia de los suportes en redes integradas de telecomunicación, con opciones tecnológicas interoperables para acceso, procesamiento y transmisión remota de mensaje, la nueva realidad hace cada vez más tenues los límites de los procesos productivos de los media tradicionales. En Brasil, la televisión digital abierta y terrestre con recepción mueble, portátil e interactiva está en proceso de implantación e ilustra las alteraciones que inciden en el planeamiento y producción de programas con aplicaciones multimedia de carácter interactivo y pervasivo. El presente trabajo propone una reflexión sobre la organización de la producción de contenido para televisión interactiva y el lugar del comunicador frente las nuevas formas de articulación con otras áreas del conocimiento.

\section{Palabras clave}

Televisión digital. Producción de televisión. Producción interactiva. 


\section{Expediente}

A revista E-Compós é a publicação científica em formato eletrônico da Associação Nacional dos Programas de Pós-Graduação em Comunicação (Compós). Lançada em 2004, tem como principal finalidade difundir a produção acadêmica de pesquisadores da área de Comunicação, inseridos em instituições do Brasil e do exterior.
E-COMPÓS I www.e-compos.org.br I E-ISSN 1808-2599

Revista da Associação Nacional dos Programas de Pós-Graduação em Comunicação. Brasília, v.12, n.3, set./dez. 2009.

A identificação das edições, a partir de 2008 passa a ser volume anual com três números.

\section{CONSELHO EDITORIAL}

Afonso Albuquerque

Universidade Federal Fluminense, Brasil

Alberto Carlos Augusto Klein

Universidade Estadual de Londrina, Brasi

Alex Fernando Teixeira Primo

Universidade Federal do Rio Grande do Sul, Brasil

Alfredo Vizeu

Universidade Federal de Pernambuco, Brasi

Ana Carolina Damboriarena Escosteguy

Pontifícia Universidade Católica do Rio Grande do Sul, Brasil

Ana Silvia Lopes Davi Médola

Universidade Estadual Paulista, Brasil

André Luiz Martins Lemos

Universidade Federal da Bahia, Brasil

Ângela Freire Prysthon

Universidade Federal de Pernambuco, Brasil

Antônio Fausto Neto

Universidade do Vale do Rio dos Sinos, Brasil

Antonio Carlos Hohlfeldt

Pontifícia Universidade Católica do Rio Grande do Sul, Brasil

Arlindo Ribeiro Machado

Universidade de São Paulo, Brasil

César Geraldo Guimarães

Universidade Federal de Minas Gerais, Brasi

Cristiane Freitas Gutfreind

Pontifícia Universidade Católica do Rio Grande do Sul, Brasil

Denilson Lopes

Universidade Federal do Rio de Janeiro, Brasil

Eduardo Peñuela Cañizal

Universidade Paulista, Brasil

Erick Felinto de Oliveira

Universidade do Estado do Rio de Janeiro, Brasil

Francisco Menezes Martins

Universidade Tuiuti do Paraná, Brasil

Gelson Santana

Universidade Anhembi/Morumbi, Brasil

Goiamérico Felício

Universidade Federal de Goiás, Brasil

Hector Ospina

Universidad de Manizales, Colômbia

Herom Vargas

Universidade Municipal de São Caetano do Sul, Brasil

leda Tucherman

Universidade Federal do Rio de Janeiro, Brasil

Itania Maria Mota Gomes

Universidade Federal da Bahia, Brasil

Janice Caiafa

Universidade Federal do Rio de Janeiro, Brasil

Jeder Silveira Janotti Junior

Universidade Federal da Bahia, Brasil

\section{João Freire Filho}

Universidade Federal do Rio de Janeiro, Brasil

John DH Downing

University of Texas at Austin, Estados Unidos

José Luiz Aidar Prado

Pontifícia Universidade Católica de São Paulo, Brasil

José Luiz Warren Jardim Gomes Braga

Universidade do Vale do Rio dos Sinos, Brasi

Juremir Machado da Silva

Pontifícia Universidade Católica do Rio Grande do Sul, Brasil

Lorraine Leu

University of Bristol, Grã-Bretanha

Luiz Claudio Martino

Universidade de Brasília, Brasil

Maria Immacolata Vassallo de Lopes

Universidade de São Paulo, Brasil

Maria Lucia Santaella

Pontifícia Universidade Católica de São Paulo, Brasil

Mauro Pereira Porto

Tulane University, Estados Unidos

Muniz Sodre de Araujo Cabral

Universidade Federal do Rio de Janeiro, Brasil

Nilda Aparecida Jacks

Universidade Federal do Rio Grande do Sul, Brasil

Paulo Roberto Gibaldi Vaz

Universidade Federal do Rio de Janeiro, Brasil

Renato Cordeiro Gomes

Pontifícia Universidade Católica do Rio de Janeiro, Brasil

Ronaldo George Helal

Universidade do Estado do Rio de Janeiro, Brasil

Rosana de Lima Soares

Universidade de São Paulo, Brasil

Rossana Reguillo

Instituto Tecnológico y de Estudios Superiores do Occidente, México

Rousiley Celi Moreira Maia

Universidade Federal de Minas Gerais, Brasil

Samuel Paiva

Universidade Federal de São Carlos, Brasil

Sebastião Albano

Universidade Federal do Rio Grande do Norte, Brasil

Sebastião Carlos de Morais Squirra

Universidade Metodista de São Paulo, Brasil

Simone Maria Andrade Pereira de Sá

Universidade Federal Fluminense, Brasi

Suzete Venturelli

Universidade de Brasília, Brasil

Valério Cruz Brittos

Universidade do Vale do Rio dos Sinos, Brasil

Veneza Mayora Ronsini

Universidade Federal de Santa Maria, Brasil

Vera Regina Veiga França

Universidade Federal de Minas Gerais, Brasi

\section{COMISSÃO EDITORIAL}

Felipe da Costa Trotta I Universidade Federal de Pernambuco, Brasil Rose Melo Rocha I Escola Superior de Propaganda e Marketing, Brasil

\section{CONSULTORES AD HOC}

Arthur Autran Franco de Sá Neto I Universidade Federal de São Carlos

Carlos Eduardo Franciscato I Universidade Federal de Sergipe

Elisa Reinhardt Piedras I Universidade Federal do Rio Grande do Su

Elizabeth Bastos Duarte I Universidade Federal de Santa Maria

Marcia Benetti Machado I Universidade Federal do Rio Grande do Sul

Sandra Maria Lúcia Pereira Gonçalves I Universidade Federal do Rio Grande do Sul

Suzana Kilpp I Universidade do Vale do Rio dos Sinos

Tattiana Gonçalves Teixeira I Universidade Federal de Santa Catarina

Vander Casaqui I Escola Superior de Propaganda e Marketing

Vicente Gosciola I Universidade Anhembi Morumbi

Walter Teixeira Lima Junior I Fundação Cásper Líbero

REVISÃO DE TEXTO E TRADUÇÃO I Everton Cardoso

EDITORAÇ̃̃ ELETRÔNICA I Raquel Castedo
COMPóS I www.compos.org.br

Associação Nacional dos Programas de Pós-Graduação em Comunicação

Presidente

Itania Maria Mota Gomes

Universidade Federal da Bahia, Brasil

itania@ufba.br

Vice-presidente

Julio Pinto

Pontifícia Universidade Católica de Minas Gerais, Brasil

juliopinto@pucminas.br

Secretária-Geral

Ana Carolina Escosteguy

Pontifícia Universidade Católica do Rio Grande do Sul, Brasil

carolad@pucrs.br 